\title{
Approaches to the Pharmacological Management of Jet Lag
}

\author{
Josephine Arendt ${ }^{1}$
}

Published online: 30 August 2018

(c) The Author(s) 2018

\begin{abstract}
For many years now a treatment mitigating the debilitating effects of jet lag has been sought. Rapid travel across time zones leads, in most people, to temporary symptoms, in particular poor sleep, daytime alertness and poor performance. Mis-timed circadian rhythms are considered to be the main factor underlying jet-lag symptoms, together with the sleep deprivation from long haul flights. Virtually all aspects of physiology are rhythmic, from cells to systems, and circadian rhythms are coordinated by a central pacemaker or clock in the suprachiasmatic nucleus (SCN) of the hypothalamus. The SCN adapts slowly to changes in time zone, and peripheral clocks or oscillators adapt at different rates, such that the organism is in a state of desynchrony from the external environment and internally. Light exposure is the main factor controlling the circadian system and needs to be considered together with any pharmacological interventions. This review covers the relatively new chronobiotic drugs, which can hasten adaptation of the circadian system, together with drugs directly affecting alertness and sleep propensity. No current treatment can instantly shift circadian phase to a new time zone; however, adaptation can be hastened. The melatoninergic drugs are promising but larger trials in real-life situations are needed. For short stopovers it is recommended to preserve sleep and alertness without necessarily modifying the circadian system. New research suggests that modification of clock function via genetic manipulation may one day have clinical applications.
\end{abstract}

\section{Key Points}

Jet lag is largely perceived as poor sleep, daytime sleepiness and mis-timed physiological functions.

Jet lag is primarily due to circadian rhythms adapting slowly to a change in time zone together with sleep deprivation during flight.

A number of timed treatments including bright light exposure, stimulants, hypnotics and drugs that shift rhythms can alleviate the symptoms of jet lag and hasten adaptation to the destination time zone.

For short stop-overs it is advised not to adapt but to preserve sleep and alertness as far as possible.

Josephine Arendt

arendtjo@gmail.com; j.arendt@surrey.ac.uk

1 Faculty of Health and Medical Sciences (FHMS), University of Surrey, Guildford, Surrey GU2 7XH, UK

\section{Introduction}

Jet lag is the inspired term for the state experienced by most people after rapid travel over several time zones. It emerged as the general public started to travel by plane to distant parts in the 1960s. Apparently the term 'jet lag' was first used in a Los Angeles Times article on 13 February 1966. "If you're going to be a member of the Jet Set and fly off to Katmandu for coffee with King Mahendra", wrote Horace Sutton, "you can count on contracting Jet Lag, a debility not unakin to a hangover. Jet Lag derives from the simple fact that jets travel so fast they leave your body rhythms behind" [1]. Essentially this is a correct description. However, the term itself has now come into widespread use to describe 'social jet lag', a state whereby body rhythms are not fully synchronised with the social/employment environment. No jets are involved and this condition will not be considered here, except to say that some of the debilitating features of jet lag may be present. The primary complaint of jet-lagged travellers is sleep disorder [2-4].

According to the International Classification of Sleep Disorders II as cited in [5], the diagnostic criteria for Jet Lag Disorder were: 
Complaint of insomnia or excessive daytime sleepiness associated with transmeridian jet travel across at least two time zones, associated impairment of daytime function, general malaise, or somatic symptoms such as gastrointestinal disturbance within one or two days after travel, sleep disturbance is not better explained by another current sleep disorder, medical or neurological disorder, mental disorder, medication use, or substance use disorder.

In fact 'jet-lag disorder' has been removed from the Diagnostic and Statistical Manual of Mental Disorders (DSM) $\mathrm{V}$ and is encompassed within the classification 'Circadian rhythm sleep disorders' [5]:

Circadian Rhythm Sleep Disorder A. A persistent or recurrent pattern of sleep disruption leading to excessive sleepiness or insomnia that is due to a mismatch between the sleep-wake schedule required by a person's environment and his or her circadian sleep-wake pattern. B. The sleep disturbance causes clinically significant distress or impairment in social, occupational, or other important areas of functioning. C. The disturbance does not occur exclusively during the course of another Sleep Disorder or other mental disorder. D. The disturbance is not due to the direct physiological effects of a substance (e.g., a drug of abuse, a medication) or a general medical condition. Specify type: Delayed Sleep Phase Type: a persistent pattern of late sleep onset and late awakening times, with an inability to fall asleep and awaken at a desired earlier time. Jet Lag Type: sleepiness and alertness that occur at inappropriate time of day relative to local time, occurring after repeated travel across more than one time zone. Shift Work Type: insomnia during the major sleep period or excessive sleepiness during the major awake period associated with night shift work or frequently changing shift work.

Numerous other symptoms are associated with jet lag since the underlying cause resides in our circadian timing system. Circadian (approximately $24 \mathrm{~h}$ ) rhythms are internally generated and by definition they persist in the absence of time cues (zeitgebers). Virtually all aspects of physiology are rhythmic. Whilst probably every cell in the body possesses a self-sustaining oscillator(s) or clock(s), this symphony of oscillators is coordinated by the central circadian clock (or pacemaker) situated in the supra-chiasmatic nuclei (SCN) of the hypothalamus [6-9]. Removal of the SCN in mammals leads to the loss of most circadian rhythms, and the SCN itself shows long-term self-sustained oscillations of circa $24 \mathrm{~h}$ in metabolism and electrical activity in vitro $[10,11]$.
An individual kept in a time-free environment (or at least with very weak time cues), manifests their own endogenous periodicity- 'free-running', an inherited characteristic. An average human endogenous period (or tau) is about $24.2 \mathrm{~h}$ according to controlled experiments $[12,13]$, although this does depend on previous experience of time cues [14], sex and ancestry [15]. To maintain 24-h periodicity they need to be reset by time cues, the most important of which is the light-dark cycle. Light of sufficient intensity, specific timing and suitable spectral composition are able to shift the circadian system by advance or delay according to a phaseresponse curve (PRC; Fig. 1) and to entrain the circadian system to the 24-h day $[16,17]$.

Entrainment means that rhythms display their optimal phase with respect to the environment (e.g. lowest core body temperature and highest melatonin rhythm at night) as well as 24-h periodicity (synchronisation without necessarily the correct phase). Bright natural sunlight is the most potent time cue (zeitgeber) and the shorter wavelengths (blue-green, $480-540 \mathrm{~nm}$ ) are the most effective [18-25]. The importance of light to entrainment is shown by many blind people with no perception of light (conscious or unconscious) who show free-running rhythms in a normal environment $[26,27]$. A short free-running period or tau is associated with morning diurnal preference (larks) and a long tau with evening preference (owls) in a normally entrained environment [28].

Other time cues include meals, exercise and social cues [29-34], but are much less potent than light. A number of hormones and drugs have zeitgeber properties (chronobiotics). In general full PRCs have not been developed for drugs

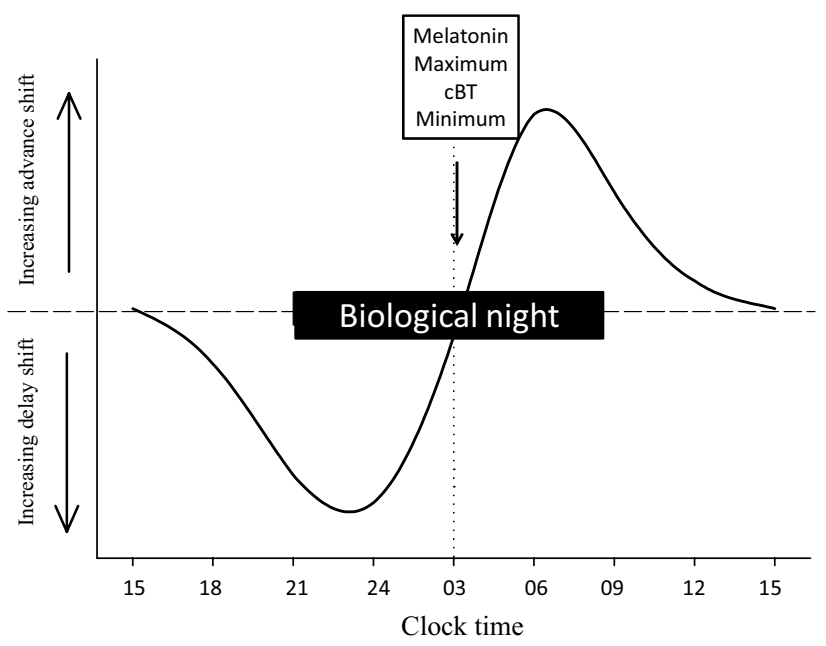

Fig. 1 Diagrammatic, simplified phase-response curve (PRC) of the light type. Light exposure prior to the melatonin maximum and cBT (core body temperature) minimum delays circadian phase and after this point advances circadian phase. Biological night is the period of melatonin secretion (see Fig. 2) 
that can act as zeitgebers, with the exception of melatonin (which is correctly a hormone, not a drug, but in supraphysiological amounts could be considered a drug).

Rapid travel across time zones leads to a mismatch or lack of synchrony between the activity of the internal rhythmgenerating systems and the local time cues, whether social or environmental. The SCN adapts slowly to abrupt changes of time cues [35-39]. On average, the central clock shifts approximately $1 \mathrm{~h}$ per day without countermeasures and it will take approximately 1 day for each hour of time zone change for adaptation to be complete. The rate of adaptation varies greatly among individuals, with the direction of time zone change (slower toward the east in general), and the rate of shift usually changes in the course of adaptation, being faster in the initial than the final stages. In addition, it is common for travellers over many time zones to adapt in the 'wrong' direction, such as by delaying $16 \mathrm{~h}$ instead of advancing $8 \mathrm{~h}$ (antidromic as compared to orthodromic adaptation) [38, 39]. Moreover, dissociation occurs amongst peripheral oscillators and between peripheral oscillators and the SCN, different systems adapting at different rates [40-44]. Thus internal rhythms are not only out of synchrony with the environment (external desynchronisation) but also out of synchrony with each other (internal desynchrony). Reentrainment by 'partition', in which some rhythms advance and some delay, has also been reported. Adapting to such phase shifts becomes harder as we grow older for uncertain reasons $[44,45]$.

Possibly one-third of all travellers do not experience jet lag. Those who do may endure short-term symptoms such as daytime tiredness, inability to get to sleep at night (after an eastward flight) or early awakening (after a westward flight), disturbed night-time sleep, impaired daytime alertness and performance, disorientation, poor performance - both cognitive and physical, gastrointestinal problems, loss of appetite, inappropriate timing of defecation, and excessive desire to urinate during the night [2, 46-53]. All of these debilitating conditions may be important for flight crew and business travellers and may ruin short holidays after a long-haul flight.

There are also possible long-term consequences of frequent desynchrony as evidenced by epidemiological and animal studies [54-62]. These include cognitive deficits, gastrointestinal problems, increased risk of cancer, obesity, metabolic syndrome, infertility and heart disease. However, not all reports are consistent, and most information is derived from shift workers who spend substantial amounts of time desynchronised - a lifetime occupational hazard.

The problem of treatment is not simple. From the traveller's point of view preserving sleep and daytime alertness and performance are the major considerations. Rapid resynchronisation addresses both these and other problems. However, circadian response to time-zone change depends on individual characteristics such as initial circadian status, tau and light sensitivity, the individual exposure to artificial and natural light in the aircraft, natural light at destination and thus the season (photoperiod), and departure and arrival time of the aircraft. Timing of meals (and possibly their constituents) together with other weak zeitgebers such as exercise, actual sleep/nap time and social cues, can be used to help reinforce (or indeed counteract) phase shifts. Some pharmacological manipulations can address the immediate problems (hypnotics, alerting agents) without necessarily affecting the circadian issues.

Much effort has been devoted to finding an efficient method of alleviating jet lag with only partial success. A major problem is the (biological) time-dependency of chronobiotics (PRC; Figs. 1, 2, 3), which may have opposite effects depending on internal circadian time of treatment. Internal circadian time is often referenced as the timing of the melatonin rhythm whereby the period of melatonin secretion is referred to as a 'biological night' (Fig. 2). Core body temperature also serves to reference circadian time (lowest in the second half of the night) but is less discrete than melatonin secretion and more subject to 'masking' effects of, for example, exercise and meals.

Many reviews have been written on the subject of jet lag. This one will concentrate on pharmacological countermeasures, to include chronobiotics (drugs that shift rhythms), hypnotics (for short-term alleviation of sleep problems) and some drugs that can maintain alertness. The importance of light exposure needs to be addressed simultaneously given its powerful phase shifting and alerting effects. The most important factor in coping with jet lag is to preserve sleep, not only countering the effects of desynchrony but also those of sleep deprivation during long flights.

\section{Hypnotics}

Sleep can of course be conserved using conventional hypnotic drugs [47, 63-65]. The most extensively used hypnotics in enabling sleep in a jet lag situation are the benzodiazepines (e.g. temazepam, triazolam (but banned in the UK), diazepam, lorazepam, chlordiazepoxide), and the so-called non-diazepine Z-drugs (e.g. Ambien (zolpidem), Zimovane (zopiclone)). All act at least primarily via enhancement of neural GABA (gamma-aminobutyric acid) activity [66]. They have their place in the management of jet lag but possible problems with side effects (e.g. [67]) and addiction (especially with the benzodiazepines) can arise. Efficiency in preserving sleep in jet-lag situations is best served by those compounds with a short duration of action. In this way hangover effects can be reduced [68, 69].

Most hypnotics, however, do not address the underlying desynchrony, and it is usually recommended to use them for 
Fig. 2 Melatonin phase markers for determination of circadian timing. Onset is often referred to as the dim light melatonin onset (DLMO). Plasma melatonin, saliva melatonin or urinary 6-sulphatoxymelatonin can all be used to define circadian phase

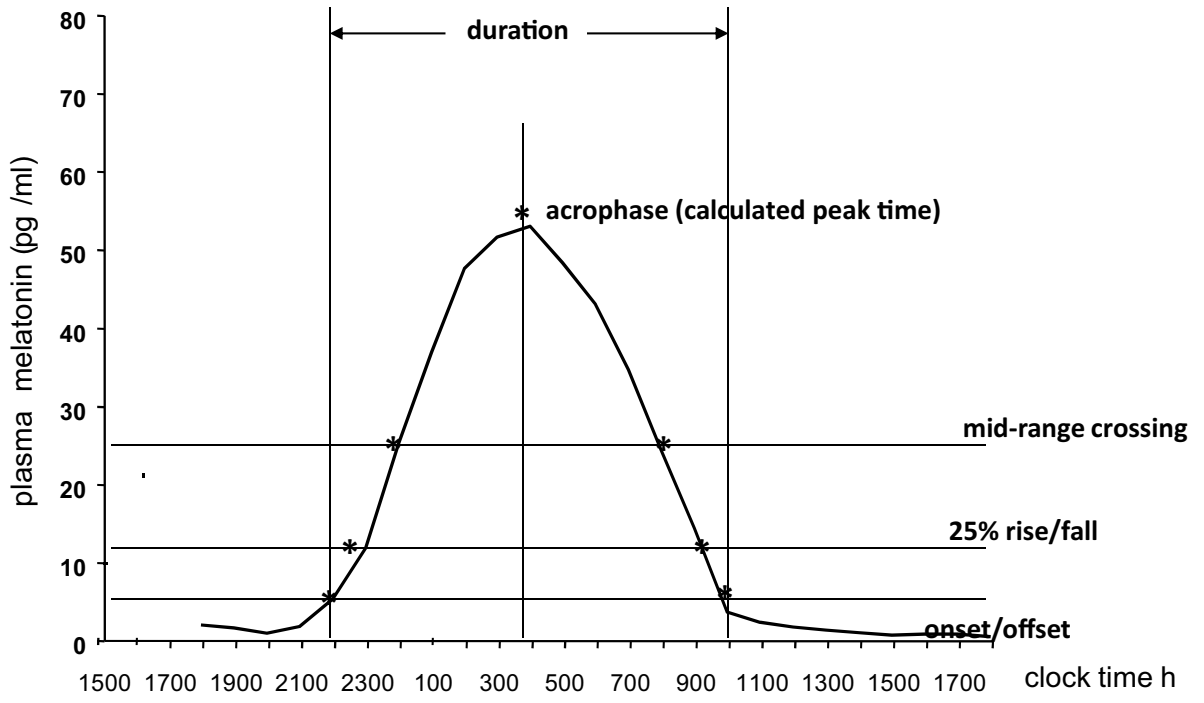

biological night

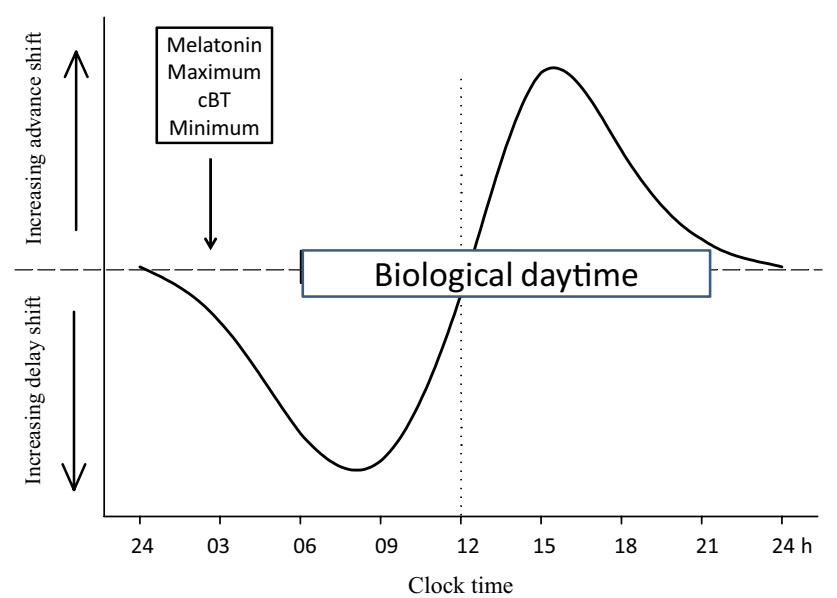

Fig. 3 Diagrammatic, simplified phase-response curve (PRC) of the melatonin type. Melatonin treatment in the late biological afternoon advances circadian phase and in early biological morning delays circadian phase. Biological night is the period of melatonin secretion (see Fig. 2)

short stopovers when adaptation is undesirable in view of the rapid return to the departure time zone. When adaptation is desirable a combination of a short-acting hypnotic and chronobiotic has been recommended together with a stimulant to maintain daytime alertness. Simultaneously careful attention to times of light exposure and avoidance is of great importance. Several published articles on detailed light exposure/avoidance exist and if followed may reduce the duration of desynchrony, with or without other manipulations (e.g. [17, 70-74]). The most recent published guide can be found at "https://books.google.com > Health \& Fitness > Sleep \& Sleep Disorders". The light regimes are not very simple to follow and unfortunately errors in timing can lead to the opposite effect of that desired. This is evident from the rapid transition from advance to delay in the PRC. The few controlled trials have proved rather inconsistent in their effects. A simplified approach is given in [36].

\section{Stimulants}

Light has been referred to as a drug with respect to its effects on alertness, sleep timing and mood [75]. Bright light, preferably sunlight, or artificial full spectrum white light has immediate alerting effects as well as phase-shifting effects on the circadian system [76, 77]. The shorter wavelengths are most effective, thus blue enriched, or monochromatic blue or green light can be used at a lower intensity than white light $[17,24,25,78,79]$. Exposure to light as an alerting agent nevertheless has to be timed such that any simultaneous phase shifts are in the direction of the fastest adaptation. Light exposure during a 'biological evening' or the rising phase of the melatonin rhythm (Fig. 2) will delay the circadian system, and during the late 'biological night', or the falling phase of the melatonin rhythm, will induce phase advances, e.g. [16]. The magnitude of the shift will depend on the intensity, spectral characteristics and duration of light exposure. Should effective light exposure fall equally on the delaying and advancing parts of the PRC, phase shifts will be negated. Avoidance of light exposure at critical times is equally important. Techniques involving the use of glasses 
blocking the powerful phase-shifting short wavelengths have been described and may be efficacious [80, 81].

It should be noted that sufficient light during the biological night will partly or wholly suppress melatonin production [17, 82, 83]. This has been invoked as part of the mechanism of light effects but not confirmed. Major light-induced shifts in magnitude and direction were not associated with changes in melatonin suppression in one report [17] and this has been confirmed in a very recent publication [84]. Suitably timed administration of exogenous melatonin can partially counter the phase-shifting effects of light [85], but more importantly can act additively with regard to phase shifts, again when correctly timed [86-88].

Caffeine is probably the most widely used psychoactive substance in the world. It has been used to maintain alertness since the first attempts to treat jet lag (e.g. Ehret CF, Scanlon LW, Overcoming jet lag, 1983, Mass Market Paperbacks). It improves alertness and performance, e.g. reaction time, vigilance and logical reasoning, in general and during extended periods with restricted opportunities for sleep [68, 89-94]. It appears to act through adenosine receptors (sleep) and through cAMP (cyclic adenosine monophosphate), a core component of the internal clocks, together with effects on dopaminergic systems [95]. Early work reported that both caffeine and the related theophylline had phase-shifting effects [96], which were not always confirmed. However, a recent publication showed clearly, in controlled conditions, that a single dose of evening caffeine could delay the circadian system, as evidenced by timing of the melatonin rhythm, by $3 \mathrm{~h}$ [97]. It remains to be seen if different timing can induce phase advances and to construct a human caffeine PRC. In general, however, it is used to maintain daytime alertness in the new time zone.

Based on the results from two small trials, the American Academy of Sleep Medicine (AASM) lists caffeine as an 'option' for the treatment of excessive sleepiness associated with JLS (jet-lag syndrome), but cautions that disturbed nocturnal sleep may result [98].

Both modafinil (Provigil) and armodafinil (Nuvigil, (R)-(-)-enantiomer of the racemic modafinil), were developed clinically for the treatment of excessive sleepiness due to narcolepsy and obstructive sleep apnoea: they originated from Lafon Laboratories in France. A consensus has emerged for their clinical use in these conditions [99-101]. They are both approved by the US Food and Drug Administration (FDA) for this use after several successful randomised, controlled clinical trials. Armodafinil due to its pharmacokinetics has a longer duration of action than modafinil. Anecdotally many off-label prescriptions for these drugs are requested for jet lag and shift-work excessive sleepiness. There is good evidence for the effectiveness of both drugs in daytime sleepiness and shift-work sleep disorder $[102,103]$. Thus given the similarity in cause and effect between shift-work sleep disorder and jet lag it is clearly of interest to investigate their use for daytime sleepiness in jet lag, and this has proved successful [103]. They are also reported to have mood-improving and memory-enhancing effects and are apparently used to treat dementia and attention deficit hyperactivty disorder (ADHD). Although the FDA has not approved either drug for maintained alertness in jet lag, it appears that they are being used as such. It would also appear that they are extensively used by the military and replace older stimulants such as amphetamines as they have less abuse potential [104]. They are also referred to as 'smart drugs', and anecdotally are used to enhance performance, memory and wakefulness for recreational activities and academic study.

The exact mode of action of these drugs is uncertain; however, increased dopamine activity is involved. Volkow and colleagues [105] published positron emission tomography imaging data in men showing that modafinil acutely increases central nervous system (CNS) dopamine. The data suggest a mechanism for modafinil that involves dopaminergic signalling, and which may be quite similar to that of older stimulants.

\section{Chronobiotics: Drugs that Shift Rhythms}

\subsection{Background}

On 1 April (!) 1983 a book 'Overcoming jet lag' by Charles F. Ehret and Lynne Scanlon, Mass Market Paperbacks (available through Amazon and see [96]) was published and became a major bestseller. Before much was known about the control of the circadian system (especially by light) this book was based essentially on diet and the manipulation of the time of coffee/tea ingestion-although exposure to bright sunlight at destination was recommended. Interestingly, food-entraining effects, notably on peripheral oscillators, have achieved subsequent prominence.

In fact chronobiotic effects of various drugs have long been known; Ehret himself described the effects of theophylline and pentobarbital [96] in animals and phase-shifting effects of drugs of abuse, e.g. methamphetamine, alcohol and fentanyl, are found in the literature. However it would probably be fair to say that melatonin was the first chronobiotic to find acceptance in clinical medicine as such, probably because of its lack of toxicity or addictive properties as well as its efficacy [106]. Evidently caffeine has been used since time immemorial as an alerting agent but usually not as a chronobiotic as only recently has this property been convincingly demonstrated $[97,101]$. 


\subsection{Melatonin}

Melatonin can induce sleep during 'biological daytime' as first reported by its discoverer Aaron Lerner, who reported that he self-administered a large dose (100 mg) [107] and the first review of its sleep-inducing properties in animals was published in 1974 [108]. It has become known as the 'sleep hormone', which is not the case. It is a 'darkness hormone', signalling the length of the night with the ability to increase sleep propensity in humans (but not in nocturnal species). We can sleep without melatonin but we sleep better when sleep is timed during the time of its secretion [109]. Essentially its endogenous role in the circadian system is to reinforce night-time physiology. It should never be forgotten that it has potent effects on seasonal physiology, e.g. reproduction, puberty and coat growth, when signalling the length of the night in photoperiodic species. For references see [110].

The synchronising properties of melatonin with regard to the activity-rest cycle were first shown in rats in 1983 [111], and its phase-shifting properties on human circadian rhythms in 1984 and 1985 with the first successful small jetlag study reported in 1986 [112-114]. It can demonstrably shift the phase of the central pacemaker or clock in the SCN in vitro [11] and in vivo, for example using its own endogenous rhythm as a marker of circadian status [106, 112, 115]. It acts via membrane melatonin MT1 and MT2 receptors $[116,117]$. In controlled experiments it shifts all measured circadian rhythms in humans [118] and can entrain freerunning rhythms in sighted and completely blind subjects $[106,119,120]$. The combination of hypnotic and chronobiotic properties is in theory ideal for a jet-lag therapy, but to exploit both requires careful timing together with control of light exposure. Optimal effects can be obtained by the use of both light and melatonin to reinforce a phase shift [86-88].

A number of small trials have, with few exceptions, provided further evidence for efficacy with regard to subjective jetlag (visual analogue scale or VAS), improved sleep and in some cases alertness and faster circadian synchronisation. The largest, randomised, blind-field study carried out over a number of years by our laboratory with 474 subjects taking melatonin and 112 taking placebo gave an average reduction in subjective jet lag (VAS) of 50\% with a very low incidence of side effects [121]. One meta-analysis confirmed the use of melatonin for jet lag using appropriate criteria for selection of trials to be included $[122,123]$. Another, assessing its use for secondary sleep disorders with no requirement for circadian desynchrony, found little effect but did consider that it was efficacious in advancing phase in delayed-sleep phase syndrome (DSPS) [124]. Its use in free-running sleep wake disorder (non-24) in the blind has not been meta-analysed, but to the author's knowledge there are no unsuccessful studies (see below for use of the agonists in the blind) [106,
120, 125-131]. The American Academy of Sleep Medicine recommends melatonin for DSPS, non-24 and jet lag [98].

The use of elite athletes as subjects for jet-lag treatment is of substantial interest especially prior to the Olympic games, in view of the circadian variations in some performance measures [132], but has been mostly disappointing. However, if the dose is wrongly timed relative to an individual circadian phase and/or bright natural light exposure, it can lead to no, or even deleterious, effects [52, 133, 134]. It is worth noting that in some cases bright light interventions and the use of temazepam were also disappointing in this population [133, 135-138].

\subsection{Timing Treatment}

Melatonin has both hypnotic and phase-shifting effects, ideal for a jet-lag drug, but timing the dose to maximise hypnotic effects (maximum during biological daytime) can compromise the phase-shifting effects (maximum during biological dawn and dusk). At this point the importance of knowing, or reliably predicting, the melatonin PRC cannot overemphasised (Fig. 3). Phase advances are generated during biological dusk just before the rise of the melatonin endogenous rhythm, and phase delays during biological dawn on the decline of the endogenous rhythm. If timing leads to a delay when an advance is needed, resynchronisation will be longer. For example, instead of advancing $8 \mathrm{~h}$ the circadian system may well delay by $16 \mathrm{~h}$ and/or re-entrain by partition.

In order to time the dose of any chronobiotic treatment according to a PRC it is thus important to determine circadian status. To do this precisely requires measurement of a 'marker' rhythm, usually melatonin itself. This is both slow and expensive, even using for example saliva sampled every 30 min evening and morning or sequential urine samples over 24-48 h (for the melatonin metabolite aMT6s, 6-sulphatoxymelatonin). This no doubt is one explanation for the very small number of large randomised, placebo-controlled, double-blind trials in the field. We have done this in field conditions using urinary aMT6s in a small trial with no problems [112, 139]. For subjects adapted to their departure time zone, circadian status can be approximately assessed using habitual sleep timing (or if possible core body temperature), and this status can be used to time treatment in the destination time zone.

\subsection{Combining Light, Sleep and Melatonin Timing}

Another strategy is to initiate an advance or delay of the clock pre-flight by timed post-sleep or pre-sleep light treatment, followed by gradually shifting both sleep and light timing as appropriate to the desired adaptation $[36,86,87$, $140,141]$. The use of timed melatonin, sleep and light treatment on a shifting schedule pre-flight can also help rapid 
adaptation [36, 86, 87, 142]. Combinations of timed light, dark, sunglasses and melatonin have been recommended to help adaptation or at least partial adaptation to night shift work [142]. But for frequent flyers, pilots and aircrew, shift workers and anyone with shifting circadian status there is no good simple method as yet. A biosensor for a circadian marker, e.g. melatonin, is needed. Moreover an automated, wearable warning system to signal appropriate light exposure or avoidance plus a signal-'time to take the pill'would be useful.

\subsection{Melatonin Agonists}

Since the discovery of melatonin receptors a large number of potential and demonstrable receptor agonists and antagonists have been developed [116, 143-147]. Two cloned receptors, MT1 and MT2, previously known as Mel1a and Mel1b [148], are of particular importance with regard to rhythm physiology and pharmacology. Using gene knockout technology in mice and pharmacological manipulations, the results to date suggest that the phase-shifting melatonin receptor in the SCN is MT2, while MT1 is associated with acute suppression of SCN electrical activity [117] and soporific effects. There appears to be some redundancy of function between these receptors with regard to circadian function. MT1 also has important actions within the pars tuberalis (PT) and the hypothalamus [145], controlling seasonal variations in ruminants [149-153]. Genetic polymorphism has been identified within melatonin membrane receptors, and further investigation of these polymorphisms in relation to photoperiodism, human disease (notably Type II diabetes), sensitivity to melatonin, and other aspects, is ongoing [154-157].

The existing, approved, commercially available melatonin agonists agomelatine (Valdoxan, Servier Pharmaceuticals), ramelteon (Rozerem, Takeda Pharmaceutials) and tasimelteon (Hetlioz, Vanda Pharmaceuticals) were designed to act via the MT1 and MT2 receptors, as does prolonged-release melatonin (Circadin, Neurim Pharmaceuticals). Their pharmacological and therapeutic properties together with their adverse effects are comprehensively summarised in Williams et al. [147]. The affinity of the most recent agonist to obtain approval - tasimelteon-is greater for the phaseshifting MT2 receptor than MT1, whereas the opposite is true for ramelteon. Slow-release melatonin and agomelatine have approximately equal affinities for both receptors [147].

Very few data are available from large randomised, placebo-controlled studies to judge their effects in jet-lag treatment. Ramelteon in one trial (75 healthy volunteers) showed significant phase shifts to adapt but with no improvement in sleep [158]. In another trial with 110 subjects who had experienced jet-lag sleep disorder, sleep latency was reduced, but with deleterious effects on performance [159].
Prolonged-release melatonin was compared with two doses of fast-release melatonin and proved less efficacious than the higher $5 \mathrm{mg}$ fast-release dose [160]. The same group also compared melatonin with zolpidem treatment and found both had beneficial effects but there was better sleep with zolpidem, albeit with substantial side effects when on this treatment [67].

Tasimelteon in a phase II and phase III simulated jet lag study (451 subjects all told, 5 -h phase advance) showed significant improvement in a number of sleep variables and a quite large phase shift in melatonin onset as a marker for circadian phase [161]. Tasimelteon was developed as a treatment specifically for the circadian (free-running) non-24 sleep disorder of the blind and is approved only for that purpose as yet. However, the developer Vanda Pharmaceuticals recently announced results of a simulation jetlag study ( $8 \mathrm{~h}$ advance of time cues) in 318 subjects with very significant improvement of sleep and daytime alertness with drug compared to placebo (http://phx.corporate-ir.net/ phoenix.zhtml?c $=196233 \& p=$ irol-newsArticle \&id $=23360$ 85). Tasimelteon thus shows the most promise for jet-lag treatment and Vanda have announced their intention to seek marketing approval for this purpose.

All of the agonists and both fast- and prolonged-release melatonin have chronobiotic effects, but clearly more data are needed in large controlled trials to judge their usefulness in real-life jet-lag situations. The original Cochrane analysis [122, 123] approved melatonin for jet lag. Updates and advice on sedatives, etc. have also been published [162-164]. The question of cost arises when considering the clinical use of agonists and approved melatonin formulations. It is difficult to find consistent information. More importantly the relative efficacy of different products compared to melatonin itself in different situations needs to be assessed.

\section{Miscellaneous}

Food entrainment of peripheral oscillators has received much attention recently. Probably the association between desynchronised states and metabolic syndrome, type II diabetes and obesity accounts for this interest $[30,41,55$, 165-168]. Most manipulations in actual jet lag have targeted the central clock but peripheral oscillators are not necessarily responsive to, for example, light treatment and may remain desynchronised for longer or shorter times than the SCN. The strategy of gradually shifting light, sleep, melatonin (and also meal times) [86] may help central and peripheral clocks to remain in synchrony. The advice to eat at the conventional time in the destination time zone is undoubtedly helpful to peripheral synchrony. Large controlled trials do not appear to exist. 
Exercise can induce phase shifts [32] but there are insufficient data to provide useful advice.

Glucocorticoids: The hormone cortisol, usually considered as the stress hormone, is intimately concerned with metabolism and the coordination of peripheral oscillators as previously mentioned. These observations merit further investigation for clinical ends. Anecdotally it has been taken to counteract jet lag as an awakening signal. The only formal clinical trial as far as the author is aware was started in 2004 comparing hydrocortisone with melatonin and placebo, but has yet to report any results: https://clinicaltrials.gov/ct2/ show/NCT00097474. However clear entraining effects of glucocorticoids on peripheral oscillators were shown in a recent study [169], suggesting that a combined treatment targeting the central clock and peripheral oscillators separately might be feasible.

Caffeine: In addition to its alerting effects, caffeine clearly needs further evaluation for jet-lag therapy. Recently, a clear demonstration of its ability to induce a large phase delay in the circadian system will hopefully encourage proper trials with careful timing and dose [97].

\section{Direct Manipulation of the SCN Molecular Machinery}

Understanding the mechanisms of circadian clock function has vastly increased in the last 20 years. Of course many chronobiologists see an instant resetting of the clock as the holy grail and the clinical importance of desynchronised rhythms has underpinned much research on the molecular biology of the circadian clock. Targets related to gene expression within the clock have been proposed for possible therapeutic development of new drugs to influence circadian rhythms.

The 24-h rhythmicity conferred by the SCN on downstream systems depends on the integrity of the SCN itself. Its intrinsic robust activity depends on coupling amongst the neural constituents [170]. Loosening of this coupling leads to faster phase shifts: in essence the $\mathrm{SCN}$ resists adaptation when acting coherently, such that unpredictable light exposure does not immediately disturb the circadian system. The gene Lhx1 (LIM homeobox 1) is reported to be central to this coupling and its loss in mice means that the SCN cells do not produce the proteins they need to synchronize their outputs. These include paracrine peptidergic signals such as VIP (vasoactive intestinal peptide), and VIP is one of the factors that maintains coupling [171, 172].

Mice deficient in VIP show desynchronization among SCN neurons [173]. Moreover, Yamaguchi et al. [174] showed that mice deficient in $\mathrm{V} 1 \mathrm{a}$ and $\mathrm{V} 1 \mathrm{~b}$ receptors were resistant to jet lag whilst having normal circadian function. VIP is present throughout the body but the VIP in the retina has neural connections to the SCN. Very recently it has been proposed that eye drops of a VIP antagonist could be used to enable rapid adaptation to a shift of the environmental light cue [175]. No clinical data exist as yet.

In a related but different pathway Jagannath et al. [176] reported that knockdown of the gene Sikl (salt-inducible kinase 1) within the SCN results in extended light-induced phase shifts and an enhanced rate of re-entrainment to an advanced light-dark cycle. As SIK1 acts to suppress the effects of light on the clock, it again provides a possible target for development of chronobiotics. However, it seems there is a long way to go with this interference in central clock molecular machinery before reliable, non-toxic, reversible, non-addictive, acceptable, cheap treatments are available.

\section{Conclusions}

Direct application of hypnotics and alertness-enhancing drugs is relatively easy to advise and applicable for short stopovers with medical advice. Numerous drugs and endogenous molecules are now known to affect functioning of the circadian system; however, none of the precise chronobiotic approaches to hasten adaptation or to pre-adapt before flight are simple. It is possible to envisage a wearable sensor to determine sleep timing and/or core body temperature preand post-departure (for approximate circadian phase), and with timing signals for, for example, melatonin administration, light exposure/avoidance, exercise and meals such that treatment timing can be optimised. Programmes for such regimes can be found on the internet but have not been trialled, to the author's knowledge. A simplistic approach to timing treatment based on known or reliably predicted circadian phase in the departure time zone (see Arendt, 2009, [36]) may help. However, for the fatigued frequent flyer with short stop-overs in a state of internal and external desynchrony there is no 'cure' to be had yet except to preserve sleep and alertness, with or without drugs.

Acknowledgements The author is grateful to numerous colleagues and students who have contributed to her research on melatonin, light and circadian rhythms, in particular Dr. Benita Middleton and Professor Debra Skene.

\section{Compliance with ethical standards}

Funding No funds were received for writing this review.

Conflict of interest The author declares no conflict of interest. Prior to 2014, the author has acted as a consultant to Vanda Pharmaceuticals. She is a director and shareholder of two companies, Stockgrand Ltd 
and Surrey Assays Ltd, concerned with measuring melatonin and its metabolites. None of these associations had any influence on the writing or content of this review.

Open Access This article is distributed under the terms of the Creative Commons Attribution-NonCommercial 4.0 International License (http://creativecommons.org/licenses/by-nc/4.0/), which permits any noncommercial use, distribution, and reproduction in any medium, provided you give appropriate credit to the original author(s) and the source, provide a link to the Creative Commons license, and indicate if changes were made.

\section{References}

1. Sutton H. https://www.airspacemag.com/need-to-know/whendid-the-term-jet-lag-come-into-use-71638/\#wuYyAiVATM YqzOzS.99. Accessed July 2018.

2. Sack RL. The pathophysiology of jet lag. Travel Med Infect Dis. 2009;7(2):102-10.

3. Haimov I, Arendt J. The prevention and treatment of jet lag. Sleep Med Rev. 1999;3(3):229-40.

4. Arendt J, Marks V. Physiological changes underlying jet lag. $\mathrm{Br}$ Med J (Clin Res Ed). 1982;284(6310):144-6.

5. Thorpy MJ. Classification of sleep disorders. Neurotherapeutics. 2012;9(4):687-701. https://doi.org/10.1007/s13311-012-0145-6 (Published online 2012 Sep 14).

6. Hastings M, O'Neill JS, Maywood ES. Circadian clocks: regulators of endocrine and metabolic rhythms. J Endocrinol. 2007;195(2):187-98.

7. Kyriacou CP, Hastings MH. Circadian clocks: genes, sleep, and cognition. Trends Cogn Sci. 2010;14(6):259-67.

8. Archer SN, Laing EE, Moller-Levet CS, van der Veen DR, Bucca G, Lazar AS, et al. Mistimed sleep disrupts circadian regulation of the human transcriptome. Proc Natl Acad Sci USA. 2014;111(6):E682-91

9. Potter GDM, Cade JE, Grant PJ, Hardie LJ. Nutrition and the circadian system. Br J Nutr. 2016;116(3):434-42.

10. Schwartz WJ, Meijer JH. Real-time imaging reveals spatiotemporal dynamics of cellular circadian clocks. Trends Neurosci. 2004;27(9):513-6.

11. McArthur AJ, Gillette MU, Prosser RA. Melatonin directly resets the rat suprachiasmatic circadian clock in vitro. Brain Res. 1991;565(1):158-61.

12. Czeisler CA, Duffy JF, Shanahan TL, Brown EN, Mitchell JF, Rimmer DW, et al. Stability, precision, and near-24hour period of the human circadian pacemaker. Science. 1999;284(5423):2177-81.

13. Middleton B, Arendt J, Stone BM. Human circadian rhythms in constant dim light (8 lux) with knowledge of clock time. J Sleep Res. 1996;5(2):69-76.

14. Scheer FA, Wright KP Jr, Kronauer RE, Czeisler CA. Plasticity of the intrinsic period of the human circadian timing system. PLoS ONE. 2007;2(1):e721.

15. Eastman CI, Tomaka VA, Crowley SJ. Sex and ancestry determine the free-running circadian period. J Sleep Res. 2017;26(5):547-50.

16. Khalsa SB, Jewett ME, Cajochen C, Czeisler CA. A phase response curve to single bright light pulses in human subjects. $\mathrm{J}$ Physiol. 2003;549(Pt 3):945-52.

17. Paul MA, Miller JC, Love RJ, Lieberman H, Blazeski S, Arendt $\mathrm{J}$. Timing light treatment for eastward and westward travel preparation. Chronobiol Int. 2009;26(5):867-90.
18. Brainard GC, Hanifin JP, Greeson JM, Byrne B, Glickman G, Gerner E, et al. Action spectrum for melatonin regulation in humans: evidence for a novel circadian photoreceptor. J Neurosci. 2001;21(16):6405-12.

19. Thapan K, Arendt J, Skene DJ. An action spectrum for melatonin suppression: evidence for a novel non-rod, non-cone photoreceptor system in humans. J Physiol. 2001;535(Pt 1):261-7.

20. Berson DM, Dunn FA, Takao M. Phototransduction by retinal ganglion cells that set the circadian clock. Science. 2002;295(5557):1070-3.

21. Lucas RJ, Peirson SN, Berson DM, Brown TM, Cooper HM, Czeisler CA, et al. Measuring and using light in the melanopsin age. Trends Neurosci. 2014;37(1):1-9.

22. Lucas RJ, Freedman MS, Munoz M, Garcia-Fernandez JM, Foster RG. Regulation of the mammalian pineal by non-rod, noncone, ocular photoreceptors. Science. 1999;284(5413):505-7.

23. Foster RG, Hankins MW. Circadian vision. Curr Biol. 2007;17(17):R746-51.

24. Lockley SW, Brainard GC, Czeisler CA. High sensitivity of the human circadian melatonin rhythm to resetting by short wavelength light. J Clin Endocrinol Metab. 2003;88(9):4502-5.

25. Revell VL, Arendt J, Fogg LF, Skene DJ. Alerting effects of light are sensitive to very short wavelengths. Neurosci Lett. 2006;399(1-2):96-100.

26. Lewy AJ, Newsome DA. Different types of melatonin circadian secretory rhythms in some blind subjects. J Clin Endocrinol Metab. 1983;56(6):1103-7.

27. Lockley SW, Skene DJ, Arendt J, Tabandeh H, Bird AC, Defrance R. Relationship between melatonin rhythms and visual loss in the blind. J Clin Endocrinol Metab. 1997;82(11):3763-70.

28. Duffy JF, Dijk DJ, Hall EF, Czeisler CA. Relationship of endogenous circadian melatonin and temperature rhythms to selfreported preference for morning or evening activity in young and older people. J Investig Med. 1999;47(3):141-50.

29. Richardson G, Tate B. Hormonal and pharmacological manipulation of the circadian clock: recent developments and future strategies. Sleep. 2000;23(Suppl 3):S77-85.

30. Challet E. Circadian clocks, food intake, and metabolism. Prog Mol Biol Transl Sci. 2013;119:105-35.

31. Johnston JD. Physiological responses to food intake throughout the day. Nutr Res Rev. 2014;27(1):107-18.

32. Atkinson G, Edwards B, Reilly T, Waterhouse J. Exercise as a synchroniser of human circadian rhythms: an update and discussion of the methodological problems. Eur J Appl Physiol. 2007;99(4):331-41.

33. Escobar C. An introduction to chrononutrition: Is when you eat as important as what you eat? Ann Nutr Metab. 2017;71(Supplement 2): 1331 .

34. Mistlberger RE, Skene DJ. Nonphotic entrainment in humans? J Biol Rhythms. 2005;20(4):339-52.

35. Buijs FN, Leon-Mercado L, Guzman-Ruiz M, Guerrero-Vargas NN, Romo-Nava F, Buijs RM. The circadian system: a regulatory feedback network of periphery and brain. Physiology. 2016;31(3):170-81.

36. Arendt J. Managing jet lag: some of the problems and possible new solutions. Sleep Med Rev. 2009;13(4):249-56.

37. Redfern P, Minors D, Waterhouse J. Circadian rhythms, jet lag, and chronobiotics: an overview. Chronobiol Int. 1994;11(4):253-65.

38. Gundel A, Wegmann HM. Transition between advance and delay responses to eastbound transmeridian flights. Chronobiol Int. 1989;6(2):147-56.

39. Takahashi T, Sasaki M, Itoh H, Yamadera W, Ozone M, Obuchi $\mathrm{K}$, et al. Re-entrainment of the circadian rhythms of plasma melatonin in an 11-h eastward bound flight. Psychiatry Clin Neurosci. 2001;55(3):275-6. 
40. Stokkan KA, Yamazaki S, Tei H, Sakaki Y, Menaker M. Entrainment of the circadian clock in the liver by feeding. Science. 2001;291(5503):490-3.

41. Dibner C, Schibler U. Circadian timing of metabolism in animal models and humans. J Intern Med. 2015;277(5):513-27.

42. Garaulet M, Gomez-Abellan P. Chronobiology and obesity. Nutr Hosp. 2013;28(Suppl 5):114-20.

43. Leise T, Siegelmann H. Dynamics of a multistage circadian system. J Biol Rhythms. 2006;21(4):314-23.

44. Moline ML, Pollak CP, Monk TH, Lester LS, Wagner DR, Zendell SM, et al. Age-related differences in recovery from simulated jet lag. Sleep. 1992;15(1):28-40.

45. Gander PH, Kronauer RE, Graeber RC. Phase shifting two coupled circadian pacemakers: implications for jet lag. Am J Physiol. 1985;249(6 Pt 2):R704-19.

46. Becker T, Penzel T, Fietze I. First jet lag symptoms after travelling across multiple time zones. Biol Rhythm Res. 2015;46(3):361-70.

47. Coste O, Lagarde D. Clinical management of jet lag: what can be proposed when performance is critical? Travel Med Infect Dis. 2009;7(2):82-7.

48. Drake CL. The characterization and pathology of circadian rhythm sleep disorders. J Fam Pract. 2010;59(SUPPL. 1):S12-7.

49. Golombek DA, Casiraghi LP, Agostino PV, Paladino N, Duhart JM, Plano SA, et al. The times they're a-changing: effects of circadian desynchronization on physiology and disease. J Physiol Paris. 2013;107(4):310-22.

50. Zhu L, Zee PC. Circadian rhythm sleep disorders. Neurol Clin. 2012;30(4):1167-91.

51. Akerstedt T. Altered sleep/wake patterns and mental performance. Physiol Behav. 2007;90(2-3):209-18.

52. Forbes-Robertson S, Dudley E, Vadgama P, Cook C, Drawer $S$, Kilduff L. Circadian disruption and remedial interventions: effects and interventions for jet lag for athletic peak performance. Sports Med. 2012;42(3):185-208.

53. Reilly T, Waterhouse J, Edwards B. Jet lag and air travel: implications for performance. Clin Sports Med. 2005;24(2):367-80 (xii).

54. Erren TC, Falaturi P, Morfeld P, Knauth P, Reiter RJ, Piekarski C. Shift work and cancer: the evidence and the challenge. Deutsch Arzteblatt Int. 2010;107(38):657-62.

55. Scheer FAJL, Hilton MF, Mantzoros CS, Shea SA. Adverse metabolic and cardiovascular consequences of circadian misalignment. Proc Natl Acad Sci USA. 2009;106(11):4453-8.

56. Arendt J. Shift work: coping with the biological clock. Occup Med (Lond). 2010;60(1):10-20.

57. Gamaldo CE, Chung Y, Kang YM, Salas RME. Tick-tock-ticktock: the impact of circadian rhythm disorders on cardiovascular health and wellness. J Am Soc Hypertens. 2014;8(12):921-9.

58. Marquie J-C, Tucker P, Folkard S, Gentil C, Ansiau D. Chronic effects of shift work on cognition: findings from the VISAT longitudinal study. Occup Environ Med. 2015;72(4):258-64.

59. Kojo K, Pukkala E, Auvinen A. Breast cancer risk among Finnish cabin attendants: a nested case-control study. Occup Environ Med. 2005;62(7):488-93.

60. Fu L, Lee CC. The circadian clock: pacemaker and tumour suppressor. Nat Rev Cancer. 2003;3(5):350-61.

61. Plano SA, Casiraghi LP, Moro PG, Paladino N, Golombek DA, Chiesa JJ. Circadian and metabolic effects of light: implications in weight homeostasis and health. Front Neurol. 2017;8(Oct):558

62. Boden MJ, Kennaway DJ. Circadian rhythms and reproduction. Reproduction. 2006;132(3):379-92.

63. Richardson GS, Mitrzyk BM, Bramley TJ. Circadian rhythmicity and the pharmacologic management of insomnia. Am J Manag Care. 2007;13(5 Suppl):S125-8.
64. Waterhouse J, Reilly T, Edwards B. The stress of travel. J Sports Sci. 2004;22(10):946-65 (discussion 65-6).

65. Cajochen C. Sleep disruption in shift work and jet lag: the role of the circadian timing system. Praxis. 2005;94(38):1479-83.

66. Doble A. New insights into the mechanism of action of hypnotics. J Psychopharmacol. 1999;13(4 Suppl 1):S11-20.

67. Suhner A, Schlagenhauf P, Hofer I, Johnson R, Tschopp A, Steffen R. Effectiveness and tolerability of melatonin and zolpidem for the alleviation of jet lag. Aviat Space Environ Med. 2001;72(7):638-46

68. Zee PC, Goldstein CA. Treatment of shift work disorder and jet lag. Curr Treat Options Neurol. 2010;12(5):396-411.

69. Buxton OM, Copinschi G, Van Onderbergen A, Karrison TG, Van Cauter E. A benzodiazepine hypnotic facilitates adaptation of circadian rhythms and sleep-wake homeostasis to an eight hour delay shift simulating westward jet lag. Sleep. 2000;23(7):915-27.

70. Houpt TA, Boulos Z, Moore-Ede MC. MidnightSun: software for determining light exposure and phase-shifting schedules during global travel. Physiol Behav. 1996;59(3):561-8.

71. Chesson AL, Littner M, Davila D, Anderson WM, Grigg-Damberger M, Hartse K, et al. Practice parameters for the use of light therapy in the treatment of sleep disorders. Standards of Practice Committee, American Academy of Sleep Medicine. Sleep. 1999;22(5):641-60.

72. Eastman CI, Burgess HJ. How to travel the world without jet lag. Sleep Med Clin. 2009;4(2):241-55.

73. Postnova S, Robinson PA. Optimization of light intervention to treat circadian misalignment. Sleep. 2017;40(Supplement 1):A254.

74. Diekman CO, Bose A. Reentrainment of the circadian pacemaker during jet lag: east-west asymmetry and the effects of northsouth travel. J Theor Biol. 2018;437:261-85.

75. Wirz-Justice A. Light and dark as a "drug". Prog Drug Res. 1987;31:383-425.

76. Cajochen C. Alerting effects of light. Sleep Med Rev. 2007;11(6):453-64.

77. Czeisler CA, Johnson MP, Duffy JF, Brown EN, Ronda JM, Kronauer RE. Exposure to bright light and darkness to treat physiologic maladaptation to night work. N Engl J Med. 1990;322(18):1253-9.

78. Lockley SW, Evans EE, Scheer FA, Brainard GC, Czeisler CA, Aeschbach D. Short-wavelength sensitivity for the direct effects of light on alertness, vigilance, and the waking electroencephalogram in humans. Sleep. 2006;29(2):161-8.

79. Revell VL, Arendt J, Terman M, Skene DJ. Short-wavelength sensitivity of the human circadian system to phase-advancing light. J Biol Rhythms. 2005;20(3):270-2.

80. Youngstrom E. Preliminary test of amber glasses as a way of resetting circadian melatonin release: randomized trial during travel from Asia. Neuropsychopharmacology. 2014;1:S562.

81. Sasseville A, Paquet N, Sevigny J, Hebert M. Blue blocker glasses impede the capacity of bright light to suppress melatonin production. J Pineal Res. 2006;41(1):73-8.

82. Lewy AJ, Wehr TA, Goodwin FK, Newsome DA, Markey SP. Light suppresses melatonin secretion in humans. Science. 1980;210(4475):1267-9.

83. Bojkowski CJ, Aldhous ME, English J, Franey C, Poulton AL, Skene DJ, et al. Suppression of nocturnal plasma melatonin and 6 -sulphatoxymelatonin by bright and dim light in man. Horm Metab Res. 1987;19(9):437-40.

84. Rahman SA, St Hilaire MA, Gronfier C, Chang AM, Santhi N, Czeisler CA, et al. Functional decoupling of melatonin suppression and circadian phase resetting in humans. J Physiol. 2018;596:2147-57. https://doi.org/10.1113/JP275501. 
85. Deacon S, Arendt J. Adapting to phase shifts, II. Effects of melatonin and conflicting light treatment. Physiol Behav. 1996;59(4-5):675-82.

86. Crowley SJ, Eastman CI. Phase advancing human circadian rhythms with morning bright light, afternoon melatonin, and gradually shifted sleep: can we reduce morning bright-light duration? Sleep Med. 2015;16(2):288-97.

87. Revell VL, Burgess HJ, Gazda CJ, Smith MR, Fogg LF, Eastman CI. Advancing human circadian rhythms with afternoon melatonin and morning intermittent bright light. J Clin Endocrinol Metab. 2006;91(1):54-9.

88. Paul MA, Gray GW, Lieberman HR, Love RJ, Miller JC, Trouborst M, et al. Phase advance with separate and combined melatonin and light treatment. Psychopharmacology. 2011;214(2):515-23.

89. Beaumont M, Batejat D, Pierard C, Van Beers P, Denis JB, Coste O, et al. Caffeine or melatonin effects on sleep and sleepiness after rapid eastward transmeridian travel. J Appl Physiol. 2004;96(1):50-8.

90. Roehrs T, Roth T. Caffeine: sleep and daytime sleepiness. Sleep Med Rev. 2008;12(2):153-62.

91. Ker K, Edwards PJ, Felix LM, Blackhall K, Roberts I. Caffeine for the prevention of injuries and errors in shift workers. Cochrane Database Syst Rev. 2010;5:CD008508.

92. Lagarde D, Chappuis B, Billaud PF, Ramont L, Chauffard F, French J. Evaluation of pharmacological aids on physical performance after a transmeridian flight. Med Sci Sports Exerc. 2001;33(4):628-34.

93. Pierard C, Beaumont M, Enslen M, Chauffard F, Tan DX, Reiter $\mathrm{RJ}$, et al. Resynchronization of hormonal rhythms after an eastbound flight in humans: effects of slow-release caffeine and melatonin. Eur J Appl Physiol. 2001;85(1-2):144-50.

94. Cajochen C. Sleep regulation. [German] Schlafregulation. Somnologie. 2009;13(2):64-71.

95. Volkow ND, Wang GJ, Logan J, Alexoff D, Fowler JS, Thanos $\mathrm{PK}$, et al. Caffeine increases striatal dopamine D2/D3 receptor availability in the human brain. Transl Psychiatry. 2015;5:e549.

96. Ehret CF, Potter VR, Dobra KW. Chronotypic action of theophylline and of pentobarbital as circadian zeitgebers in the rat. Science. 1975;188(4194):1212-5.

97. Burke TM, Markwald RR, McHill AW, Chinoy ED, Snider JA, Bessman SC, et al. Effects of caffeine on the human circadian clock in vivo and in vitro. Sci Transl Med. 2015;7(305):305ra146.

98. Morgenthaler TI, Lee-Chiong T, Alessi C, Friedman L, Aurora $\mathrm{RN}$, Boehlecke B, et al. Practice parameters for the clinical evaluation and treatment of circadian rhythm sleep disorders. An American Academy of Sleep Medicine report. Sleep. 2007;30(11):1445-59.

99. Barateau L, Lopez R, Dauvilliers Y. Management of narcolepsy. Curr Treat Options Neurol. 2016;18(10):43.

100. Takenoshita S, Nishino S. Pharmacologic management of excessive daytime sleepiness. Sleep Med Clin. 2017;12(3):461-78.

101. Schwartz JRL. Pharmacologic management of daytime sleepiness. J Clin Psychiatry. 2004;65(Suppl 16):46-9.

102. Czeisler CA, Walsh JK, Roth T, Hughes RJ, Wright KP, Kingsbury $\mathrm{L}$, et al. Modafinil for excessive sleepiness associated with shift-work sleep disorder. N Engl J Med. 2005;353(5):476-86.

103. Rosenberg RP, Bogan RK, Tiller JM, Yang R, Youakim JM, Earl $\mathrm{CQ}$, et al. A phase 3, double-blind, randomized, placebo-controlled study of armodafinil for excessive sleepiness associated with jet lag disorder. Mayo Clin Proc. 2010;85(7):630-8.

104. Lagarde D. Pharmacological approach to desychronization of the sleep-wakefulness cycle in the military and sport environment. Annales Pharmaceutiques Francaises. 2007;65(4):258-64.

105. Volkow ND, Fowler JS, Logan J, Alexoff D, Zhu W, Telang $\mathrm{F}$, et al. Effects of modafinil on dopamine and dopamine transporters in the male human brain: clinical implications. JAMA. 2009;301(11):1148-54.

106. Arendt J, Skene DJ. Melatonin as a chronobiotic. Sleep Med Rev. 2005;9(1):25-39.

107. Lerner AB, Nordlund JJ. Melatonin: clinical pharmacology. J Neural Transm Suppl. 1978;13:339-47.

108. Cramer H, Rudolph J, Consbruch U, Kendel K. On the effects of melatonin on sleep and behavior in man. Adv Biochem Psychopharmacol. 1974;11:187-91.

109. Dijk DJ, Shanahan TL, Duffy JF, Ronda JM, Czeisler CA. Variation of electroencephalographic activity during non-rapid eye movement and rapid eye movement sleep with phase of circadian melatonin rhythm in humans. J Physiol. 1997;505(Pt 3):851-8.

110. Arendt J. Melatonin: characteristics, concerns, and prospects. J Biol Rhythms. 2005;20(4):291-303.

111. Redman J, Armstrong S, Ng KT. Free-running activity rhythms in the rat: entrainment by melatonin. Science. 1983;219(4588):1089-91.

112. Arendt J, Bojkowski C, Folkard S, Franey C, Marks V, Minors D, et al. Some effects of melatonin and the control of its secretion in humans. Ciba Found Symp. 1985;117:266-83.

113. Arendt J, Aldhous M, Marks V. Alleviation of jet lag by melatonin: preliminary results of controlled double blind trial. Br Med J (Clin Res Ed). 1986;292(6529):1170.

114. Arendt J, Borbely AA, Franey C, Wright J. The effects of chronic, small doses of melatonin given in the late afternoon on fatigue in man: a preliminary study. Neurosci Lett. 1984;45(3):317-21.

115. Lewy AJ, Bauer VK, Ahmed S, Thomas KH, Cutler NL, Singer $\mathrm{CM}$, et al. The human phase response curve (PRC) to melatonin is about 12 hours out of phase with the PRC to light. Chronobiol Int. 1998;15(1):71-83.

116. Dubocovich ML. Melatonin receptors: role on sleep and circadian rhythm regulation. Sleep Med. 2007;8(Suppl 3):34-42.

117. Liu J, Clough SJ, Hutchinson AJ, Adamah-Biassi EB, PopovskaGorevski M, Dubocovich ML. MT1 and MT2 melatonin receptors: a therapeutic perspective. Annu Rev Pharmacol Toxicol. 2016;56:361-83.

118. Rajaratnam SM, Dijk DJ, Middleton B, Stone BM, Arendt J. Melatonin phase-shifts human circadian rhythms with no evidence of changes in the duration of endogenous melatonin secretion or the 24-hour production of reproductive hormones. J Clin Endocrinol Metab. 2003;88(9):4303-9.

119. Middleton B, Arendt J, Stone BM. Complex effects of melatonin on human circadian rhythms in constant dim light. J Biol Rhythms. 1997;12(5):467-77.

120. Arendt J, Aldhous M, Wright J. Synchronisation of a disturbed sleep-wake cycle in a blind man by melatonin treatment. Lancet. 1988;1(8588):772-3.

121. Arendt J, Skene DJ, Middleton B, Lockley SW, Deacon S. Efficacy of melatonin treatment in jet lag, shift work, and blindness. J Biol Rhythms. 1997;12(6):604-17.

122. Herxheimer A, Petrie KJ. Melatonin for preventing and treating jet lag. Cochrane Database Syst Rev. 2001;1:CD001520.

123. Herxheimer A, Petrie KJ. Melatonin for the prevention and treatment of jet lag. Cochrane Database Syst Rev. 2002;2:CD001520.

124. Buscemi N, Vandermeer B, Hooton N, Pandya R, Tjosvold L, Hartling L, et al. Efficacy and safety of exogenous melatonin for secondary sleep disorders and sleep disorders accompanying sleep restriction: meta-analysis. Bmj. 2006;332(7538):385-93.

125. Hack LM, Lockley SW, Arendt J, Skene DJ. The effects of lowdose 0.5 -mg melatonin on the free-running circadian rhythms of blind subjects. J Biol Rhythms. 2003;18(5):420-9.

126. Lewy AJ, Emens JS, Lefler BJ, Yuhas K, Jackman AR. Melatonin entrains free-running blind people according to a physiological dose-response curve. Chronobiol Int. 2005;22(6):1093-106. 
127. Lockley SW, Skene DJ, James K, Thapan K, Wright J, Arendt J. Melatonin administration can entrain the free-running circadian system of blind subjects. J Endocrinol. 2000;164(1):R1-6.

128. Lockley SW, Arendt J, Skene DJ. Visual impairment and circadian rhythm disorders. Dialogues Clin Neurosci. 2007;9(3):301-14.

129. Sack RL, Lewy AJ, Blood ML, Keith LD, Nakagawa H. Circadian rhythm abnormalities in totally blind people: incidence and clinical significance. J Clin Endocrinol Metab. 1992;75(1):127-34.

130. Skene DJ, Arendt J. Circadian rhythm sleep disorders in the blind and their treatment with melatonin. Sleep Med. 2007;8(6):651-5.

131. Sack RL, Brandes RW, Kendall AR, Lewy AJ. Entrainment of free-running circadian rhythms by melatonin in blind people. N Engl J Med. 2000;343(15):1070-7.

132. Meijer JH, Deboer T, Michel S. In time for Beijing: influence of the biological clock on athletic performance. Nederlands Tijdschrift voor Geneeskunde. 2008;152(33):1809-12.

133. Edwards BJ, Atkinson G, Waterhouse J, Reilly T, Godfrey $\mathrm{R}$, Budgett R. Use of melatonin in recovery from jet-lag following an eastward flight across 10 time-zones. Ergonomics. 2000;43(10):1501-13.

134. Atkinson G, Buckley P, Edwards B, Reilly T, Waterhouse J. Are there hangover-effects on physical performance when melatonin is ingested by athletes before nocturnal sleep? Int $\mathbf{J}$ Sports Med. 2001;22(3):232-4.

135. Atkinson G, Drust B, Reilly T, Waterhouse J. The relevance of melatonin to sports medicine and science. Sports Med. 2003;33(11):809-31.

136. Reilly $\mathrm{T}$. The body clock and athletic performance. Biol Rhythm Res. 2009;40(1):37-44.

137. Thompson A, Batterham AM, Jones H, Gregson W, Scott D, Atkinson G. The practicality and effectiveness of supplementary bright light for reducing jet-lag in elite female athletes. Int J Sports Med. 2013;34(7):582-9.

138. Reilly T, Atkinson G, Budgett R. Effect of low-dose temazepam on physiological variables and performance tests following a westerly flight across five time zones. Int J Sports Med. 2001;22(3):166-74.

139. Arendt J, Aldhous M, Marks M, Folkard S, English J, Marks V, et al. Some effects of jet-lag and their treatment by melatonin. Ergonomics. 1987;30:1379-93.

140. Smith MR, Revell VL, Eastman CI. Phase advancing the human circadian clock with blue-enriched polychromatic light. Sleep Med. 2009;10(3):287-94.

141. Smith MR, Eastman CI. Phase delaying the human circadian clock with blue-enriched polychromatic light. Chronobiol Int. 2009;26(4):709-25.

142. Crowley SJ, Lee C, Tseng CY, Fogg LF, Eastman CI. Combinations of bright light, scheduled dark, sunglasses, and melatonin to facilitate circadian entrainment to night shift work. J Biol Rhythms. 2003;18(6):513-23.

143. Pévet P. Melatonin receptors as therapeutic targets in the suprachiasmatic nucleus. Expert Opin Ther Targets. 2016;20(10):1209-18.

144. Reppert SM. Melatonin receptors: molecular biology of a new family of $\mathrm{G}$ protein-coupled receptors. J Biol Rhythms. 1997;12(6):528-31.

145. Masana MI, Dubocovich ML. Melatonin receptor signaling: finding the path through the dark. Sci STKE. 2001;2001(107):pe39.

146. Nickelsen T, Samel A, Vejvoda M, Wenzel J, Smith B, Gerzer R. Chronobiotic effects of the melatonin agonist LY 156735 following a simulated $9 \mathrm{~h}$ time shift: results of a placebo-controlled trial. Chronobiol Int. 2002;19(5):915-36.
147. Williams WP, McLin DE, Dressman MA, Neubauer DN. Comparative review of approved melatonin agonists for the treatment of circadian rhythm sleep-wake disorders. Pharmacotherapy. 2016;36(9):1028-41.

148. Reppert SM, Weaver DR, Godson C. Melatonin receptors step into the light: cloning and classification of subtypes. Trends Pharmacol Sci. 1996;17(3):100-2.

149. Morgan PJ, Hazlerigg DG. Photoperiodic signalling through the melatonin receptor turns full circle. J Neuroendocrinol. 2008;20(6):820-6.

150. Lincoln GA. Neuroendocrine regulation of seasonal gonadotrophin and prolactin rhythms: lessons from the Soay ram model. Reprod Suppl. 2002;59:131-47.

151. Dardente H. Melatonin-dependent timing of seasonal reproduction by the pars tuberalis: pivotal roles for long daylengths and thyroid hormones. J Neuroendocrinol. 2012;24(2):249-66.

152. Klosen P, Bienvenu C, Demarteau O, Dardente H, Guerrero H, Pévet $\mathrm{P}$, et al. The mt1 melatonin receptor and RORbeta receptor are co-localized in specific TSH-immunoreactive cells in the pars tuberalis of the rat pituitary. J Histochem Cytochem. 2002;50(12):1647-57.

153. Hut RA. Photoperiodism: shall EYA compare thee to a summer's day? Curr Biol. 2011;21(1):R22-5.

154. Bonnefond A, Froguel P. Disentangling the role of melatonin and its receptor MTNR1B in type 2 diabetes: still a long way to go? Curr Diab Rep. 2017;17(12):122.

155. Bouatia-Naji N, Bonnefond A, Cavalcanti-Proença C, Spars $\varnothing$ T, Holmkvist J, Marchand M, et al. A variant near MTNR1B is associated with increased fasting plasma glucose levels and type 2 diabetes risk. Nat Genet. 2009;41(1):89-94.

156. Lyssenko V, Nagorny CL, Erdos MR, Wierup N, Jonsson A, Spégel P, et al. Common variant in MTNR1B associated with increased risk of type 2 diabetes and impaired early insulin secretion. Nat Genet. 2009;41(1):82-8.

157. Trecherel E, Batailler M, Chesneau D, Delagrange P, Malpaux B, Chemineau P, et al. Functional characterization of polymorphic variants for ovine MT1 melatonin receptors: possible implication for seasonal reproduction in sheep. Anim Reprod Sci. 2010;122(3-4):328-34.

158. Richardson GS, Zee PC, Wang-Weigand S, Rodriguez L, Peng $X$. Circadian phase-shifting effects of repeated ramelteon administration in healthy adults. J Clin Sleep Med. 2008;4(5):456-61.

159. Zee PC, Wang-Weigand S, Wright KP Jr, Peng X, Roth T. Effects of ramelteon on insomnia symptoms induced by rapid, eastward travel. Sleep Med. 2010;11(6):525-33.

160. Suhner A, Schlagenhauf P, Johnson R, Tschopp A, Steffen $\mathrm{R}$. Comparative study to determine the optimal melatonin dosage form for the alleviation of jet lag. Chronobiol Int. 1998;15(6):655-66.

161. Rajaratnam SM, Polymeropoulos MH, Fisher DM, Roth T, Scott C, Birznieks G, et al. Melatonin agonist tasimelteon (VEC-162) for transient insomnia after sleep-time shift: two randomised controlled multicentre trials. Lancet. 2009;373(9662):482-91.

162. Herxheimer A, Petrie KJ. Review: oral melatonin reduces jet lag in air travellers. Evid Based Med. 2001;6(6):186.

163. Herxheimer A. Jet lag. Clin Evid. 2004;11:2243-8.

164. Herxheimer A. Jet lag. BMJ. Clin Evid. 2008;2008:2303.

165. Broussard JL, Van Cauter E. Disturbances of sleep and circadian rhythms: novel risk factors for obesity. Curr Opin Endocr Diabetes Obes. 2016;23(5):353-9.

166. Garaulet M, Gomez-Abelln P, Madrid JA. Chronobiology and obesity: the orchestra out of tune. Clin Lipidol. 2010;5(2):181-8.

167. Mayeuf-Louchart A, Zecchin M, Staels B, Duez H. Circadian control of metabolism and pathological consequences of clock perturbations. Biochimie. 2017;143:42-50. 
168. Morgan L, Hampton S, Gibbs M, Arendt J. Circadian aspects of postprandial metabolism. Chronobiol Int. 2003;20(5):795-808.

169. Cuesta M, Cermakian N, Boivin DB. Glucocorticoids entrain molecular clock components in human peripheral cells. FASEB J. 2015;29(4):1360-70.

170. Hatori M, Gill S, Mure LS, Goulding M, O'Leary DD, Panda S. Lhx 1 maintains synchrony among circadian oscillator neurons of the SCN. Elife. 2014;3:e03357.

171. Welsh DK, Takahashi JS, Kay SA. Suprachiasmatic nucleus: cell autonomy and network properties. Annu Rev Physiol. 2010;72:551-77.

172. Hogenesch JB, Herzog ED. Intracellular and intercellular processes determine robustness of the circadian clock. FEBS Lett. 2011;585(10):1427-34.
173. Aton SJ, Colwell CS, Harmar AJ, Waschek J, Herzog ED. Vasoactive intestinal polypeptide mediates circadian rhythmicity and synchrony in mammalian clock neurons. Nat Neurosci. 2005;8(4):476-83.

174. Yamaguchi Y, Suzuki T, Mizoro Y, Kori H, Okada K, Chen Y, et al. Mice genetically deficient in vasopressin V1a and V1b receptors are resistant to jet lag. Science. 2013;342(6154):85-90.

175. Tsuji T, Allchorne AJ, Zhang M, Tsuji C, Tobin VA, Pineda R, et al. Vasopressin casts light on the suprachiasmatic nucleus. J Physiol. 2017;595(11):3497-514.

176. Jagannath A, Butler R, Godinho SIH, Couch Y, Brown LA, Vasudevan SR, et al. The CRTC1-SIK1 pathway regulates entrainment of the circadian clock. Cell. 2013;154(5):1100-11. 